\title{
Requirements for a Value Stream Mapping in Make-To-Order Environments
}

\author{
Christoph Koch and Hermann Lödding \\ Hamburg University of Technology, Hamburg, Germany \\ \{christoph.koch, loedding\} @tuhh.de
}

\begin{abstract}
Value stream mapping (VSM) is a widely proven method to optimize a production. The practical approach, the manageable effort and the targetoriented procedure are the factors of success of this method. However, the method is of limited use when applied to make-to-order (MTO) environments. This paper aims to describe the shortcomings of VSM with respect to an application in a MTO production. The paper concentrates on the different logistic targets VSM impacts, as well as the manufacturing control tasks VSM applies. To set the basis for an application of VSM in MTO companies, requirements are described both for the logistic targets of VSM and the related manufacturing control tasks.
\end{abstract}

Keywords: value stream mapping, make-to-order, production control.

\section{Introduction}

It's not only the quality and the price of products but also the quality of logistic processes that satisfy customer demands. Especially for make-to-order companies, high delivery reliability is mandatory to satisfy the customer [1]. Value Stream Mapping (VSM) is a widely proven and powerful tool in the field of continuous improvement of logistic targets. It has been established as a de facto standard in the industrial environment. It is composed of common rules that help to support targets like low inventory levels, short throughput times and high productivity [2]. It was developed as a communication standard within the high-volume-low-mix (HVLM) industry [3]. Thus, the method is tailored to the needs of the corresponding production system. Its implicit assumptions (make-to-stock) and explicit recommendations (design guidelines) are of limited use for make-to-order (MTO) companies. Companies with a high number of variants particularly criticize structural problems of the method [4]. Therefore, we seek for an approach to apply this practical method even in a MTO environment.

This paper analyzes the shortcomings of VSM with respect to an application in the field of MTO. The analysis allows formulating requirements for a MTO specific VSM. The focus lays on the logistic targets and on the involved methods of manufacturing control. 


\section{Make-To-Order Production}

Production can be divided into different manufacturing strategies that come along with different characteristics. The manufacturing strategy usually depends on the type of product a company produces. In this context make-to-order (MTO) and make-tostock (MTS) are two ideal types of processing an order. These two concepts differ in several criteria [5]:

The customer decoupling point describes the point in the value chain, where the product is linked to a specific customer order. A MTS production usually produces according to forecasts without concrete customer orders. The customer orders are satisfied by stocks of finished goods. Contrary to that, manufacturing orders in MTO companies are initialized directly by customers. A customer order triggers a manufacturing order, so that every manufacturing order can be connected to a customer [6].

MTS companies often produce standard products without any customer specific influence on the product design. Customers are then accustomed to a limited choice of products. In a MTO environment the influence of the customer on the product is usually higher, so that the number of different products is typically much higher than in a MTS production and the volume per product is much lower [7].

According to the range of products, the structure of the products also differs. While MTS companies often produce low priced products with a simple structure, MTO companies typically have multi-part products with complex structures [6].

MTS companies typically organize their production as a flow production. The workstations are arranged according to the flow of material. The number of variants that can be produced is limited. MTO companies have complex and customer specific products, so the flow of material is normally undirected and complex. Due to this fact the manufacturing often is arranged as a workshop production to guarantee high flexibility. A job shop is a typical form of this arrangement [5].

Both types of firms also differ in their logistic targets. MTS companies serve their customers from a stock. Therefore, it is necessary to have the relevant parts available to immediately satisfy the customer demand. For MTO firms the logistic target is different. Keeping the promised delivery date is one of the most important targets for MTO companies [8].

\section{$3 \quad$ Value Stream Mapping}

Value Stream Mapping is the process of picturing both the material flow and the information flow to coordinate all activities [9]. VSM is divided into two stages: analysis and design. Rother and Shook deliver a standard procedure for drawing the current state map [3]. This procedure can be separated into five steps that should be followed in order to generate the current state map: 1) Select a product family; 2) Collect the relevant data; 3) Incorporate the information flow; 4) Draw the timeline; 5) Interpret the current state map.

After having established the current state map, the question arises how to get to a future state map. The design stage provides structured guidelines that lead to future 
state maps. Rother and Shook propose seven guidelines [3]: 1) Produce to takt time; 2) Implement continuous flow and FIFO lanes; 3) Use Kanban supermarkets; 4) Send the production planning information only to the pacemaker; 5) Level the product mix evenly; 6) Distribute the production volume evenly (batch sizes); 7) Manufacture every part every day.

By applying these guidelines, a future state map can be developed stepwise. The guidelines represent the standard configuration for a manufacturing control system for a MTS production.

\section{Shortcomings of Conventional VSM for MTO Productions}

The discrepancy between the conventional VSM and a MTO production can be illustrated by three points: Differences in logistic objectives, a mismatch of the applied tasks of manufacturing control and the manufacturing environment.

\subsection{Logistic Objectives}

Both types of companies, MTS and MTO, differ in logistic objectives amongst other criteria (see chapter 2). As the conventional VSM is tailored to a MTS environment, the method also inherits the logistic objectives of a MTS production. The conventional VSM thus omits the most important logistic objective in MTO environments: schedule reliability.

Schedule reliability is one of the most important internal logistic objectives for MTO companies [10]. The schedule reliability describes the stability of logistic processes within a production [11]. It directly affects the delivery reliability towards the customer. It is defined as the percentage of orders completed within a defined range of tolerance [12]. The schedule reliability is influenced by the lateness and by the sequence deviation. Kuyumcu developed a causal model that is able to separate the overall lateness into lateness resulting from backlog and lateness resulting from sequence deviation [13]. The current VSM ignores the schedule reliability as an important key figure for MTO companies.

In the analysis stage of the conventional VSM the focus lays on work-in-progress (WIP) and throughput time (TTP). The former key figure is directly recorded during the value stream analysis, the latter derived from the WIP level and the customer takt. Both figures are important also for MTO companies. However, the measurement method of both figures is not practicable for MTO companies. The WIP is measured in number of parts. This is sufficient and practicable for companies with standard products and standardized container contents. Recording the number of parts in a MTO environment with highly fluctuating processing times and batch sizes can be less helpful. Usually, the number of parts is not representative for the workload of the orders and the counting itself can be time-consuming if there are no standard container contents. The throughput time is calculated with Little's Law by dividing the WIP level in front of the workstation by the customer takt. However, the customer takt is hardly to determine in a MTO production as the material flow is more complex and the order contents are varying strongly. 


\subsection{Applied Functions of Manufacturing Control}

The design stage of VSM includes methods for controlling manufacturing in terms of guidelines. These guidelines act in accordance with the logistic objectives of a MTS production. In the section below the guidelines are evaluated with respect to their use in a MTO production:

1. Produce to takt time: The customer takt is highly fluctuating in a MTO environment, so that it is much more difficult to produce to takt time than in high volume MTS productions.

2. Develop continuous flow with FIFO sequencing: Due to highly fluctuating processing times and complex material flows the implementation of continuous flow is often not applicable in MTO productions. The FIFO lanes help to avoid a chaotic sequencing in MTO productions as well. However, they do not support schedule reliability because delayed orders won't be accelerated when they are processed in their incoming sequence.

3. Use Kanban supermarkets to control production: The Kanban method is by definition a decentralized order generation mechanism for companies that produce to stock. In this case the Kanaban logic is responsible to refill the consumption of a stock / supermarket. Thus, it is not applicable for a MTO production.

4. Send the production planning information only to the pacemaker: The PPC information should only be sent to the pacemaker process, so that not all processes are controlled by a superior production planning department. The upstream processes should be decoupled by Kanban supermarkets, which is not possible for MTO companies.

5. Level the product mix evenly: To level the product mix evenly at the pacemaker process one need to have a good forecast of the individual demands and to know a constant pacemaker / bottleneck system. Both points can often not be achieved in MTO environments.

6. Distribute the production volume evenly: After leveling the product mix in the next step the production volume should be distributed evenly on the pacemaker process. This is often not possible to install immediately as it is necessary to know the exact demands and a stable pacemaker process.

7. Build the capability to produce every part every day: Building up the capability to produce every part every day means to decrease setup times and batch sizes to react flexible on changes in demand. Generally, this guideline is also useful for MTO companies. By reducing setup times the need for building setup families disappears.

Some of the guidelines, generally those who manage the informational flow, are based on a stable pacemaker process. As a MTO production often arranges their manufacturing in form of a job shop with complex and changing material flows, a stable pacemaker often is hardly to achieve. Quite the contrary: job shops have complex flows of material and changing bottlenecks. Other guidelines directly assume the functions of the manufacturing control tasks, e.g. installing supermarkets and FIFOlanes. This is reasonable for a MTS, but not for a MTO production. The supermarkets 
connect the processes that are located upstream of the pacemaker process and stock semi-finished goods. Downstream of the pacemaker workstation, a continuous flow should be established with FIFO sequencing. As mentioned before, FIFO does not support the schedule reliability.

\subsection{Missing Functions of Manufacturing Control}

The guidelines aim to optimize the manufacturing area by introducing and accomplishing functions of manufacturing control in a structured manner. Both the information and the material flow are controlled to improve the logistic objectives WIP and throughput time. The following figure describes the relationship between the logistic objectives of a manufacturing system and the relevant tasks of manufacturing control to achieve the objectives.

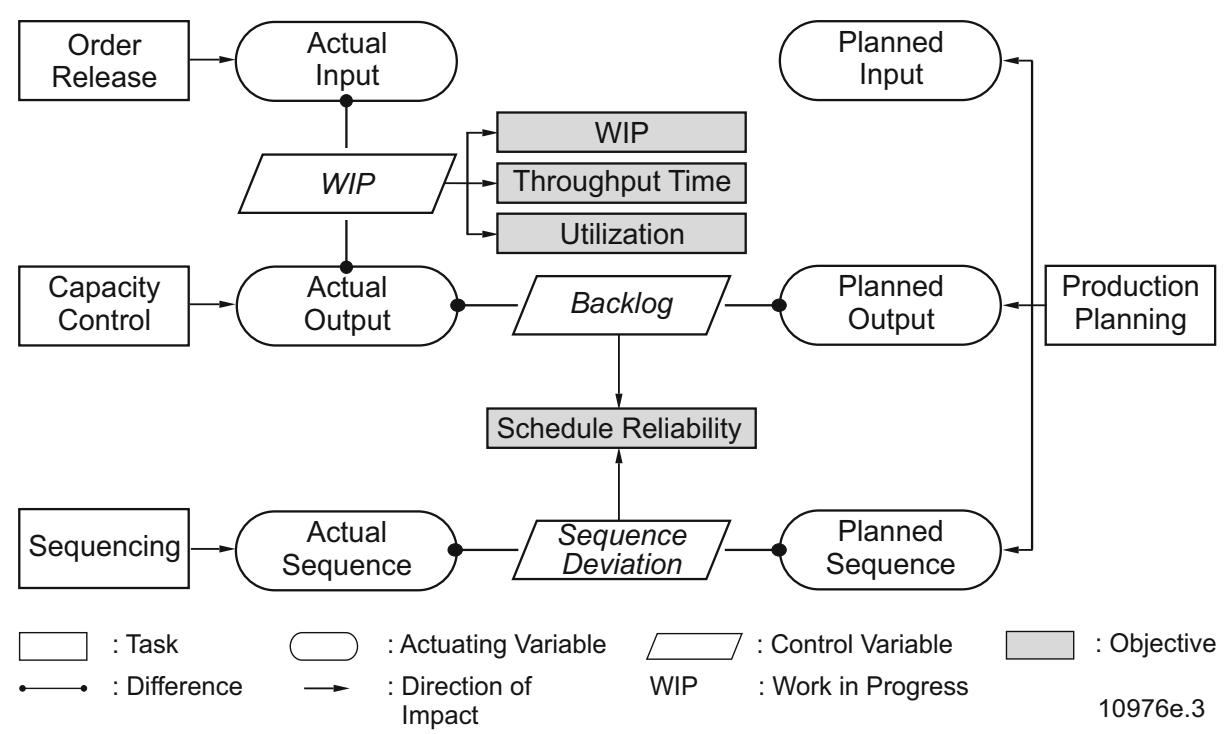

Fig. 1. A manufacturing control model [13]

The model contains tasks of manufacturing control that impact the logistic objectives of a production with the help of actuating and control variables. These tasks can be roughly divided in production planning (Fig. 1 right hand section) and production control (Fig. 1 left hand section) tasks. The model includes the following control tasks: order release, capacity control and sequencing.

While sequencing is handled by the conventional VSM approach (FIFO-lanes) both order release and capacity control are not taken into consideration. As mentioned before, FIFO sequencing does not support the schedule reliability actively. It merely avoids sequencing at the discretion of the operators, who sometimes may pursue different objectives than schedule reliability. 
The capacity control is one of the two levers to control the schedule reliability. It decides about the adjustment of capacity which can mean overtime or shortened work hours [14]. The current VSM method completely neglects the capacity control. This is very problematic even for MTS environments, as backlogs can accumulate and affect the inventory level in the supermarket. It is even more problematic for MTO companies, as backlogs directly influence schedule reliability.

By releasing an order, the production is allowed to process the order. The order release can operate based on different criteria (e.g. WIP, due dates), which have to be defined. The order release provides a lever to control the work in progress and the throughput time in a MTO production. The need and effectiveness of a structured order release to control the mean throughput time have been quoted by several authors $[15,16,17]$. It is thus an elementary function of manufacturing control, which is missing in the conventional VSM.

\section{Requirements for a VSM for MTO Productions}

The shortcomings of the conventional VSM were partially mentioned by other authors without drawing structured conclusions $[18,19]$. However, the shortcomings can be translated into requirements for an adapted VSM that is applicable on a MTO production. These requirements affect the value stream analysis as well as the value stream design.

\subsection{Requirements for a Value Stream Analysis}

The production systems of MTS and MTO companies differ. This concerns the logistic goals the production tries to achieve as well as the complexity of the production itself. Thus, the following requirements for a MTO tailored VSM arise:

1. Take into consideration all the relevant logistic objectives:

Besides the productivity oriented measures, the main measures considered by the conventional VSM are logistic objectives. Thus, within the value stream analysis all relevant logistic objectives and their control variables must be recorded. As in the conventional VSM, all measurements should be recorded directly on the shop floor. The WIP should be grasped in a unit more convenient for MTO environments. The throughput time depends on the WIP, so this relation must also be considered while choosing the appropriate units.

The schedule reliability depends on the lateness of orders, which is influenced by backlog and sequence deviation [12]. Similar to the relation of WIP and throughput time, backlog and sequence deviation act as control variables for the schedule reliability. Both measures then have to be recorded in the analysis stage of the MTO tailored VSM.

2. Cover the complexity of job shops:

The first step of the analysis contains the choice of an adequate product family using a product-process-matrix. Having a large amount of product families, this procedure becomes very extensive. A VSM for MTO should rather focus on the 
entirety of work systems than on single product families. By doing this, the procedure will be to cover the complexity of production systems of MTO companies, such as backflows or shared resources.

\subsection{Requirements for a Value Stream Design}

For a VSM that is tailored for a MTO production new requirements regarding the guidelines occur.

1. The guidelines should consider all tasks of manufacturing control:

It is not sufficient to concentrate on single tasks of manufacturing control. In order to configure the manufacturing control comprehensively, all the relevant tasks of manufacturing control must be considered. To have a lever on the control variable WIP, the order release mechanism must be controlled. The backlog results from the difference of actual and planned output. Thus, it is fundamental to configure the capacity control task, which directly affects the actual output. Additionally, the sequencing rule must be configured to minimize sequence deviations. Planned due dates of operations are often determined during the production planning. Thus, sequencing the orders according to their due dates could be possible.

2. The guidelines should support the user with developing a future state map:

The configuration of a comprehensive manufacturing control system is a complex task. Thus, it is elementary to have a structured process for the configuration. The guidelines must support this by offering a consistent and logical sequence of introducing the manufacturing control tasks. Moreover, the guidelines should be independent of each others, so that the failure of one guideline does not automatically lead to the failure of another guideline.

\section{Conclusion and Outlook}

The paper evaluates the conventional VSM method with respect for a use in a MTO environment. Based on the field of application, the logistic targets aimed at by VSM do not correspond with the logistic targets of a MTO company. From this follows that the manufacturing control functions introduced by the value stream design, which should support the target achievement, also are either incomplete or impracticable for MTO productions. A VSM tailored for MTO should aim at all logistic objectives, especially at the schedule reliability. Therefore the appropriate manufacturing control tasks have to be considered, including order release, capacity control, and sequencing.

The ongoing studies at the IPMT include the development of a value stream analysis and a value stream design procedure. Therefore, a recording method for the logistic objectives as well as a standard configuration of manufacturing control for MTO companies must be developed and evaluated. Guidelines to develop a future state map must then be derived from the standard configuration of manufacturing control. Furthermore, the complete method has to be evaluated with different industrial partners to cover different types of MTO productions. 


\section{References}

1. Kingsman, B., Hendry, L., Mercer, A., de Souza, A.: Responding to customer enquiries in make-to-order companies - Problems and solutions. Int. J. Production Economics, 46-47, 219-231 (1996)

2. Irani, S.A., Zhou, J.: Value stream mapping of a complete product. Available at: Department of Industrial, Welding and Systems Engineering. The Ohio State University, Columbus (2011)

3. Rother, M., Shook, J.: Learning to see: Value stream mapping to create value and eliminate muda. The Lean Enterprise Institute, Brookline (1999)

4. Hämmerle, M., Rally, P.: Wertschöpfung steigern. In: Spath, D. (ed.). Fraunhofer Verlag, Stuttgart (2010)

5. Schuh, G.: Produktionsplanung und -steuerung - Grundlagen, Gestaltung, Konzepte. Springer, Berlin (2006)

6. Deep, A., Guttridge, P., Dani, S., Burns, N.: Investigating factors affecting ERP selection in made-to-order SME sector. Journal of Manufacturing Technology Management 19, 430-446 (2004)

7. Aslan, B., Stevenson, M., Hendry, L.C.: Enterprise Resource Planning systems: An assessment of applicability to Make-To-Order companies. Computers in Industry 63, 692705 (2012)

8. Nyhuis, P., Wiendahl, H.-P.: Fundamentals of Production Logistics. Springer, Berlin (2009)

9. Jones, D.T., Womack, J.P.: Seeing the Whole: Mapping the Extended Value Stream. The Lean Enterprise Institute, Brookline (2002)

10. Lödding, H., Nyhuis, P., Schmidt, M., Kuyumcu, A.: Modelling lateness and schedule reliability: how companies can produce on time. Production Planning \& Control 25, 59-72 (2014)

11. Wiendahl, H.-P.: Wie aus der Logistik eine Wissenschaft wurde. In: Wiendahl, H.-P. (ed.) Die wandlungsfähige Fabrik. Integrierte Sicht von Fabrikstruktur, Logistik und Produktionssystemen. Proceedings of the IFA-Fachtagung, pp. 107-142 (2003)

12. Yu, K.-W.: Terminkennlinie. Eine Beschreibungsmethodik für die Terminabweichung im Produktionsbereich. VDI Progress Reports, Düsseldorf (2001)

13. Kuyumcu, A.: Modellierung der Termintreue in der Produktion. PhD-Thesis, Hamburg Technical University, Hamburg (2013)

14. Lödding, H.: Handbook of Manufacturing Control. Spinger, Berlin (2013)

15. Land, M., Gaalman, G.: Workload Control concepts in job shops: a critical assessment, Igls, Austria. Preprints of the Eight International Working Seminar on Production Economics, pp. 201-226 (1994)

16. Hendry, L.C., Kingsman, B.G., Cheung, P.: The effect of workload control (WLC) on performance in make-to-order companies. Journal of Operations Management 16, 63-75 (1997)

17. Wiendahl, H.-P.: Load-oriented manufacturing control. Springer, Berlin (1995)

18. Chitturi, G., Paulls, F.: Value Stream Mapping in a Jobshop. In: Proceedings of International Conference on Agile Manufacturing, pp. 142-147 (2007)

19. Alves, T.D., Tommelein, I., Ballard, G.: Value Stream Mapping for Make-to-Order Products in a Job Shop. In: Proceedings of Construction Research Congress, pp. 1-10 (2005) 